\title{
DAMPAK SOSIAL EKONOMI PENGARUH ERUPSI SINABUNG TERHADAP PENDAPATAN, PENDIDIKAN DAN KESEHATAN MASYARAKAT DI KABUPATEN KARO
}

\author{
Juliana Simbolon ${ }^{1)}$ Posman HP Marpaung ${ }^{2)}$ Roida Sinaga ${ }^{3)}$ Gita Lestari $^{4)}$

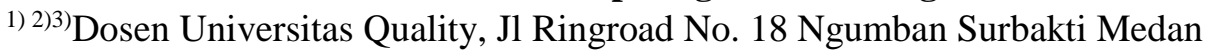 \\ 4) Mahasiswa Universitas Quality \\ Email : julianauq@gmail.com
}

\begin{abstract}
ABSTRAK
Dalam penelitian ini, ada beberapa hal yang dapat menggambarkan kondisi sosial ekonomi petani yang memiliki perbedaan pendapatan, pendidikan, dan tingkat kesehatan, antara lain: 1. Tingkat pendapatan tertinggi adalah di Desa Siosar Suka Meriah, karena mereka menerima pemerintah bantuan dalam bentuk tanah, dana, pupuk bersubsidi, dan benih, sementara di Desa Kuta Tengah Penghasilan lebih rendah karena pemerintah hanya menyediakan tempat tinggal sementara. Minimnya modal juga menyebabkan minimnya pendapatan dan lahan menjadi tidak memungkinkan bertani karena terletak di lereng Gunung Sinabung. 2. Tingkat pendidikan di Desa Siosar Suka Meriah lebih rendah, karena setelah pindah ke relokasi jarak ke sekolah terlalu jauh dan beberapa anak tidak ingin melanjutkan pendidikan mereka. Padahal di Desa Kuta Tengah Hunian pendidikan mereka lebih tinggi, karena jarak ke sekolah tidak terlalu jauh dan kebanyakan anak juga memiliki keinginan untuk pergi ke sekolah. 3. Tingkat kesehatan di Desa Siosar Suka Meriah dan tingkat kesehatan di Tempat Tinggal Desa Kuta Tengah bersama-sama menggunakan BPJS /KIS yang diprogram oleh pemerintah untuk komunitas pengungsi letusan Gunung Sinabung.
\end{abstract}

Kata kunci: dampak, Sinabung, pendapatan, pendidikan, kesehatan

\begin{abstract}
In this study, there are several things that can describe the socio-economic conditions of farmers having differences in income, education, and health levels, among others: 1. The highest level of income is in Siosar Suka Meriah Village, because they receive government assistance in the form of land, funds, subsidized fertilizers, and seeds, while in Kuta Tengah Village Shelter the income is lower because the government only provides temporary shelter. The lack of capital also caused the lack of income and land to not allow farming because it was located on the slopes of Mount Sinabung. 2. The education level in Siosar Suka Meriah Village is lower, because after moving to relocation the distance to school is too far and some children do not want to continue their education. Whereas in Kuta Tengah Village Shelter their education is higher, because the distance to school is not too far away and most children also have the desire to go to school. 3. The health level in Siosar Suka Meriah Village and the level of health in the Kuta Tengah Village Shelter together use BPJS / KIS which is programmed by the government for the Mount Sinabung eruption refugee community.
\end{abstract}

Keywords: impact, Sinabung, income, education, health 


\section{PENDAHULUAN}

Indonesia adalah negara yang beriklim tropis yang membuat tanah yang ada didalamnya adalah subur, tidak hanya itu Indonesia juga dikenal dengan salah satu negara yang memiliki Gunung berapi terbanyak didunia baik itu yang masih aktif maupun yang sudah tidak aktif, hal itulah yang membuat tanah yang ada di Indonesia menjadi subur. Namun selain membawa hal baik Gunung berapi juga dapat menimbulkan bencana yang luar biasa apabila sedang meletus. Gunung Sinabung salah satu Gunung dataran tinggi Karo, Kabupaten Karo, Sumatera Utara, Indonesia. Sinabung bersama Gunung Sibayak didekatnya adalah dua Gunung berapi aktif yang ada di Sumatera Utara.

\section{Rumusan Masalah}

1.Seperti apa pendapatan masyarakat terhadap proses relokasi Siosar dan Hunian Sementara?

2. Seperti apa tingkat pendidikan petani di Siosar dan Hunian Sementara?

3. Bagaimana tingkat kesehatan di Siosar dan Hunian Sementara?

\section{Tujuan Penelitian}

Berdasarkan latar belakang masalah yang telah diuraikan maka tujuan yang ingin dicapai dari penelitian ini yakni :

1. Mengidentifikasi pendapatan masyarakat di Siosar dan Hunian Sementara.

2. Menganalisis kondisi tingkat pendidikan petani di Siosar dan Hunian Sementara.

3. Mengkaji bagaimana tingkat kesehatan di Siosar dan Hunian Sementara.

\section{METODE PENELITIAN \\ 1.Tipe Penelitian}

Metode penelitian yang digunakan dalam penelitian ini adalah metode deskriptif kualitatif, yaitu berusaha menggambarkan secara jelas dampak pasca meletusnya Gunung Sinabung terhadap kondisi sosial ekonomi di Desa Suka Meriah Dan Masyarakat Hunian Sementara Desa Kuta Tengah Kabupaten Karo.

\section{Lokasi Penelitian}

Penelitian ini dilakukan di Desa Suka Meriah Dan Masyarakat Hunian Sementara di Desa Kuta Tengah Kabupaten Karo. Alasan penelitian memilih lokasi tersebut karena Desa Suka Meriah termasuk salah satu Desa yang terkena dampak pasca meletusnya Gunung Sinabung di Kabupaten Karo.

\section{Populasi dan Sampel}

\subsection{Populasi}

Populasi dalam penelitian ini di Desa Suka Meriah yang berjumlah 362 (KK) dan satu orang dari setiap keluarga yang tinggal di Huntara Desa Kuta Tengah yang berjumlah 267 (KK).

\subsection{Sampel}

Sampel adalah sebagian dari populasi yang diambil datanya dengan menggunakan cara-cara tertentu (Nawawi, 2004:144), jika jumlah populasi lebih dari 100 maka diambil sampelnya sejumlah $10-15 \%$ atau 20 $25 \%$ dari populasi. Maka peneliti menetapkan besarnya sampel dalam peneliti ini adalah $10 \%$ dari jumlah populasi, yaitu $10 \%$ x $629=62,9$ sampel dari Siosar 36 orang dan sampel dari Huntara 27 orang berarti sampel dalam penelitian ini adalah $\mathbf{6 3}$ orang. Sedangkan tehnik pengambilan sampel dalam penelitian ini dengan menggunakan tehnik simpel random 
sampling dimana semua anggota populasi secara individu memiliki kesempatan yang sama dijadikan sampel atau untuk dijadikan sampel atau untuk menjadi anggota sampel.

\subsection{Tehnik Pengumpulan Data}

Penelitian ini pengumpulan data yang dipakai dalam penelitian ini adalah

\section{Data Primer}

Data primer diperoleh dari penelitian lapangan yang dilakukan turun langsung kelapangan untuk mengumpulkan data melalui :

a. Penyebaran angket langsung (kuesioner), yaitu alat mengumpulkan data dengan menyebarkan angket yang berisikan pertanyaan-pertanyaan atau angket secara tertulis yang harus diisi oleh responden.

b. Wawancara yaitu pengumpulan data dengan cara memberikan pertanyaan langsung kepada responden guna memperoleh keterangan dalam menyimpulkan data yang terkumpul.

2. Data Skunder

Data skunder diperoleh data studi keputusan yaitu dengan membuka,mengutip, data dari bukubuku, laporan-laporan, penelitian, jurnal-jurnal, pendapat-pendapat para ahli/pakar dan sebagainya yang berhubungan dengan masalah penelitian dan dapat mendukung terlaksananya penelitian ini.

\subsection{Tehnik Analisis Data}

Tehnik analisis data dalam penelitian ini menggunakan metode analisa deskriptif kualitatif yang membahas tingkat pendapatan, pendidikan, kesehatan. Berdasarkan hipotesis 1, maka metodologi yang digunakan adalah deskriptif kualitatif, dimana terdapat perbedaan pendapatan ekonomi petani atau masyarakat relokasi Siosar dan Hunian Sementara pasca erupsi Gunung Sinabung. Berdasarkan hipotesis 2, maka metodologi yang digunakan adalah deskriptif kualitatif, dimana adanya perbedaan tingkat pendidikan di Siosar dan Hunian Sementara pasca erupsi Gunung Sinabung. Berdasarkan hipotesis 3, maka metodologi yang digunakan adalah deskriptif kualitatif, dimana terdapat perbedaan penggunaan asuransi kesehatan BPJS/KIS di Siosar dan Hunian Sementara.

\section{HASIL DAN PEMBAHASAN \\ 1. Deskripsi Hasil Penelitian}

Data yang diperoleh dari kuisoner sebanyak 63 (angket) dengan beberapa pertanyaan yang di tanyakan kepada petani (wawancara). Hal ini dilakukan untuk memudahkan pengambilan data 36 (angket) di relokasi Siosar Desa Suka Meriah dan 27 (angket) di Huntara Desa Kuta Tengah.

\section{Karateristik Responden}

Karateristik erupsi Gunung Sinabung di Kabupaten Karo dimulai sejak tahun 2010 hingga saat ini yang mengakibatkan kondisi sosial ekonomi petani di bidang pendapatan, pendidikan, kesehatan sangat dipengaruhi oleh erupsi Gunung Sinabung. 
1. Pendapatan Siosar dan Huntara

Tabel 1. Pendapatan Responden petani di Siosar

\begin{tabular}{|c|c|c|c|}
\hline No & Pendapatan $(\mathrm{Pd})$ & Pengeluaran(TR) & Total pendapatan(TC) \\
\hline 1 & Rp.5.500.000 & Rp.2.370.000 & Rp.3.130.000 \\
\hline 2 & Rp.4.700.000 & Rp. 2.600 .000 & Rp. 2.100 .000 \\
\hline 3 & Rp.5.900.000 & Rp.2.245.000 & Rp.3.655.000 \\
\hline 4 & Rp.4.500.000 & Rp.2.625.000 & Rp.1.875.000 \\
\hline 5 & Rp.4.000.000 & Rp.1.970.000 & Rp.2.030.000 \\
\hline 6 & Rp.3.800.000 & Rp.1.892.000 & Rp.1.908.000 \\
\hline 7 & Rp.3.900.000 & Rp.1.915.000 & Rp.1.985.000 \\
\hline 8 & Rp.4.200.000 & Rp.2.485.000 & Rp.1.715.000 \\
\hline 9 & Rp.6.000.000 & Rp.2.062.000 & Rp.3.938.000 \\
\hline 10 & Rp.5.000.000 & Rp.2.370.000 & Rp.2.630.000 \\
\hline 11 & Rp.5.500.000 & Rp.2.625.000 & Rp.2.875.000 \\
\hline 12 & Rp.4.300.000 & Rp.1.645.000 & Rp.2.655.000 \\
\hline 13 & Rp.6.000.000 & Rp.2.330.000 & Rp.3.670.000 \\
\hline 14 & Rp.4.000.000 & Rp.1.995.000 & Rp.2.005.000 \\
\hline 15 & Rp.4.500.000 & Rp.2.650.000 & Rp. 1.850 .000 \\
\hline 16 & Rp.5.500.000 & Rp.2.555.000 & Rp.2.945.000 \\
\hline 17 & Rp.4.200.000 & Rp.2.115.000 & Rp.2.085.000 \\
\hline 18 & Rp.3.900.000 & Rp.1.760.000 & Rp.2.140.000 \\
\hline 19 & Rp.4.600.000 & Rp.2.565.000 & Rp.2.035.000 \\
\hline 20 & Rp.4.800.000 & Rp.2.815.000 & Rp.1.985.000 \\
\hline 21 & Rp.5.100.000 & Rp.2.027.000 & Rp.3.073.000 \\
\hline 22 & Rp.5.400.000 & Rp.2.685.000 & Rp.2.715.000 \\
\hline 23 & Rp.6.000.000 & Rp.2.730.000 & Rp.3.270.000 \\
\hline 24 & Rp.6.500.000 & Rp.2.785.000 & Rp.3.715.000 \\
\hline 25 & Rp.3.800.000 & Rp.2.650.000 & Rp.1.150.000 \\
\hline 26 & Rp.4.400.000 & Rp.2.650.000 & Rp.1.750.000 \\
\hline 27 & Rp.5.100.000 & Rp.2.475.000 & Rp.2.625.000 \\
\hline 28 & Rp.4.800.000 & Rp.3.150.000 & Rp.1.650.000 \\
\hline 29 & Rp.5.300.000 & Rp.3.030.000 & Rp.2.270.000 \\
\hline 30 & Rp.4.000.000 & Rp.2.150.000 & Rp.1.850.000 \\
\hline 31 & Rp.4.100.000 & Rp.2.330.000 & Rp.1.770.000 \\
\hline 32 & Rp.5.000.000 & Rp.2.600.000 & Rp.2.400.000 \\
\hline 33 & Rp.6.000.000 & Rp.3.200.000 & Rp.2.800.000 \\
\hline 34 & Rp.6.500.000 & Rp.2.850.000 & Rp.3.650.000 \\
\hline 35 & Rp.5.300.000 & Rp.2.650.000 & Rp.2.650.000 \\
\hline 36 & Rp.5.500.000 & Rp.3.150.000 & Rp.2.350.000 \\
\hline Total & Rp.177.600.000 & Rp.88.701.000 & Rp.88.899.000 \\
\hline \multicolumn{3}{|c|}{ Sumber data primer, 2018} & $=2.469 .416$ \\
\hline
\end{tabular}


Dari tabel diatas dapat kita simpulkan bahwa Total pendapatan Siosar sebesar Rp. 88.899 .000 diabagi 36 responden jadi rata rata pendapatan 2.469.416/ orang / musim tanam.

\section{Pendapatan petani di Huntara}

Tabel 2. Pendapatan Responden petani di Huntara

\begin{tabular}{|c|c|c|c|}
\hline No & Pendapatan $(\mathrm{Pd})$ & Pengeluaran(TR) & Total pendapatan(TC) \\
\hline 1 & Rp.3.200.000 & Rp.1.720.000 & Rp.1.480.000 \\
\hline 2 & Rp.3.600.000 & $\begin{array}{ll}\text { Rp. } & 890.000 \\
\end{array}$ & Rp.2.710.000 \\
\hline 3 & Rp.3.100.000 & Rp.2.070.000 & Rp.1.030.000 \\
\hline 4 & Rp.3.250.000 & Rp.1.600.000 & Rp.1.650.000 \\
\hline 5 & Rp.3.500.000 & Rp.1.640.000 & Rp.1.860.000 \\
\hline 6 & Rp.3.600.000 & Rp.2.220.000 & Rp.1.380.000 \\
\hline 7 & Rp.3.400.000 & Rp.1.540.000 & Rp.1.860.000 \\
\hline 8 & Rp.3.800.000 & Rp.1.260.000 & Rp.2.540.000 \\
\hline 9 & Rp.3.350.000 & Rp.1.120.000 & Rp.2.230.000 \\
\hline 10 & Rp.3.400.000 & Rp.1.640.000 & Rp.1.760.000 \\
\hline 11 & Rp.3.600.000 & Rp.1.500.000 & Rp.2.100.000 \\
\hline 12 & Rp.3.100.000 & Rp.1.620.000 & Rp.1.480.000 \\
\hline 13 & Rp.3.400.000 & Rp.1.140.000 & Rp.2.260.000 \\
\hline 14 & Rp.3.650.000 & Rp.1.760.000 & Rp.1.890.000 \\
\hline 15 & Rp.3.400.000 & Rp.2.350.000 & Rp.1.050.000 \\
\hline 16 & Rp.3.200.000 & Rp.1.300.000 & Rp.1.900.000 \\
\hline 17 & Rp.3.150.000 & Rp.1.400.000 & Rp.1.750.000 \\
\hline 18 & Rp.3.500.000 & Rp.1.960.000 & Rp.1.540.000 \\
\hline 19 & Rp.3.800.000 & Rp.2.330.000 & Rp.1.470.000 \\
\hline 20 & Rp.3.500.000 & Rp.2.680.000 & $\begin{array}{ll}\text { Rp. } & 820.000 \\
\end{array}$ \\
\hline 21 & Rp.3.800.000 & Rp.2.100.000 & Rp.1.700.000 \\
\hline 22 & Rp.3.700.000 & Rp.3.000.000 & Rp. 700.000 \\
\hline 23 & Rp.3.750.000 & Rp.2.300.000 & Rp.1.450.000 \\
\hline 24 & Rp.3.300.000 & Rp.2.280.000 & Rp.1.020.000 \\
\hline 25 & Rp.3.400.000 & Rp.1.860.000 & Rp.1.540.000 \\
\hline 26 & Rp.3.800.000 & Rp.2.400.000 & Rp.1.400.000 \\
\hline 27 & Rp.3.900.000 & Rp.2.450.000 & Rp.1.450.000 \\
\hline \multicolumn{2}{|c|}{ Total Rp. 94.150 .000} & Rp. 50.135.000 & Rp.44.015.000 \\
\hline \multicolumn{3}{|c|}{ umber data primer, 2018} & $=$ Rp. 1.630 .185 \\
\hline
\end{tabular}

Dari tabel diatas dapat kita simpulkan bahwa Total pendapatan bersih di huntara sebesar Rp. 44.015.000 dibagi 27 responden jadi rata rata pendapatan Rp.1.630.185/ orang / musim tanam. Pembahasan : Berdasarkan tabel diatas bahwa pedapatan keseluruhan siosar sebesar Rp. 177.600.00 dan pengeluaran sebesar Rp.88.701.000 dari pengeluaran tersebut sudah termasuk biaya mengolah lahan, biaya tanam,biaya ongkos panen dan biaya membeli pupuk dan pestisida dan pendapatan bersih sebesar Rp. 88.899.000. sedangkan pendapatan keseluruhan huntara sebesar Rp.94.150.000 dan pengeluaran sebesar 
Rp.50.135.000 dari pengeluaran tersebut sudah termasuk biaya mengolah lahan,biaya tanam,biaya ongkos panen dan biaya membeli pupuk dan pestisida dan pendapatan bersih huntara sebesar Rp. 44.015.000. Dapat kita simpulkan pendapatan tertinggi terdapat di desa
Siosar sebesar Rp. 88.899.000 dari 36 responden pendapatan rata rata $\mathrm{Rp}$. 2.469.416 sedangkan Huntara sebesar Rp. 44.015.000 dari 27 responden pendapatan rata-rata Rp. 1.630.185.

\section{Tingkat Pendidikan anak di Siosar}

Tabel 3. Tingkat tertinggi Pendidikan anak di Siosar

\begin{tabular}{|c|c|c|c|}
\hline NO & Tingkat & Jumlah & Persentase \\
\hline 1 & PAUD & 1 & $0,27 \%$ \\
\hline 2 & SD & 3 & $0,81 \%$ \\
\hline 3 & SMP & 12 & $2,97 \%$ \\
\hline 4 & SMA & 20 & $95,71 \%$ \\
\hline 5 & SARJANA & 0 & 0 \\
\hline & Total & 36 Orang & $100 \%$ \\
\hline
\end{tabular}

Sumber data primer, 2018

Berdasarkan tabel diatas tingkat pendidikan tertinggi terdapat pada tingkat

SMA 20 Orang di tingkat persentase 95,71 $\%$

\section{Tingkat Pendidikan anak di Huntara}

Tabel 4. Tingkat tertinggi Pendidikan anak di Huntara

\begin{tabular}{|c|c|c|c|}
\hline NO & Tingkat & Jumlah & Persentase \\
\hline 1 & PAUD & 1 & $0,27 \%$ \\
\hline 2 & SD & 3 & $0,81 \%$ \\
\hline 3 & SMP & 5 & $1,31 \%$ \\
\hline 4 & SMA & 2 & $0,54 \%$ \\
\hline 5 & SARJANA & 16 & $96,71 \%$ \\
\hline & Total & 27 Orang & $100 \%$ \\
\hline
\end{tabular}

Sumber data primer, 2018

Berdasarkan tabel diatas tingkat pendidikan tertinggi terdapat pada tingkat SARJANA 16 Orang di tingkat persentase $96,71 \%$. berdasarkan tabel diatas pendidikan tertinggi di desa Huntara Kuta Tengah yaitu sarjana 16 orang dengan tingkat persentase $96,71 \%$ sedangkan di siosar desa suka meriah dominan SMA 20 Orang dengan tingkat persentase 95,71\%. Dapat disimpulkan bahwa tingkat pendidikan di Huntara Kuta Tengah lebih tinggi dibanding pendidikan di siosar desa suka meriah. 
5. Tingkat kesehatan di Siosar

Tabel 5. Tingkat kesehatan di Siosar

\begin{tabular}{|c|c|c|c|}
\hline No & Jumlah & Jumlah & Persentase \\
\hline 1. & BPJS & 27 & $100 \%$ \\
\hline 2. & KIS & 0 & $0 \%$ \\
\hline & Total & 27 Orang & $100 \%$ \\
\hline
\end{tabular}

Sumber data primer, 2018

Berdasarkan tabel diatas dari 27

Responden semua menggunakan BPJS

programkan oleh pemerintah kepada

yaitu persentase $100 \%$ yang di

pengungsi.

6. Tingkat kesehatan di Huntara

Tabel 6. Tingkat kesehatan di Huntara

\begin{tabular}{|c|c|c|c|}
\hline No & Jumlah & Jumlah & Persentase \\
\hline 1. & BPJS & 36 & $100 \%$ \\
\hline 2. & KIS & 0 & $0 \%$ \\
\hline & Total & 27 Orang & $100 \%$ \\
\hline
\end{tabular}

Sumber data primer, 2018

Berdasarkan tabel diatas dari 27

Responden semua menggunakan BPJS yaitu persentase $100 \%$ yang di programkan oleh pemerintah kepada pengungsi.

\section{KESIMPULAN DAN SARAN}

\section{A. Kesimpulan}

Berdasarkan hasil penelitian ini, dapat disimpulkan beberapa hal mengenai kondisi sosial ekonomi petani memiliki perbedaan dari tingkat pendapatan, pendidikan, dan kesehatan

1. Tingkat pendapatan tertinggi terdapat di Siosar Desa Suka Meriah, karena mereka mendapat bantuan dari pemerintah berupa lahan, dana/modal, pupuk subsidi, dan bibit sedangkan di Huntara Desa Kuta Tengah pendapatannya lebih rendah karena

2. pemerintah hanya memberikan tempat tinggal sementara. Kurangnya modal juga sebagai penyebab kurangnya pendapatan dan lahan juga tidak mengizinkan untuk bercocok tanam karena berada di lereng kaki Gunung Sinabung.

3. Tingkat pendidikan di Siosar Desa Suka Meriah lebih rendah, karena setelah pindah ke relokasi jarak kesekolah terlalu jauh dan sebagian anak tidak mau melanjutkan pendidikan. Sedangkan di Huntara Desa Kuta Tengah pendidikannya lebih tinggi, karena jarak tempuh kesekolah tidak terlalu jauh dan anak juga kebanyakan memiliki keinginan untuk bersekolah. 
4. Tingkat kesehatan di Siosar Desa Suka Meriah dan Tingkat kesehatan di Huntara Desa Kuta Tengah sama-sama menggunakan BPJS/KIS yang di programkan oleh pemerintah untuk masyarakat pengungsi erupsi Gunung Sinabung.

\section{B. Saran}

Berdasarkan kesimpulan penelitian, maka penulis merekomendasikan berupa saransaran sebagai berikut :

1. Untuk meningkatkan pendapatan, harapan petani agar pemerintah tetap memberikan bantuan di Siosar Desa Suka Meriah. Sedangkan untuk Huntara Desa Kuta Tengah agar pemerintah menggantikan lahan yang baru untuk bercocok tanam dan memberikan bantuan berupa dana/modal untuk mengolah lahan tersebut.

2. Supaya pemerintah mendirikan sekolah di Siosar agar anak dapat melanjutkan pendidikan. Di Huntara agar pemerintah memberikan bantuan beasiswa atau memberikan baju sekolah dan buku secara gratis.

3. Agar pemerintah tetap memperhatikan kesehatan para pengungsi dan mendirikan puskesmas serta memberikan vitamin kepada para pengungsi.

\section{DAFTAR PUSTAKA}

Herlambang, T., Sugiarto, B., Said, K. 2001. Ekonomi Makro: Teori, Analisis, dan Kebijakan. PT Gramedia Pustaka Utama: Jakarta.

Ilham,N. 2010. "Dampak Erupsi Gunung Merapi Terhadap Kondisi Sosial Ekonomi Petani”. Pusat Sosial Ekonomi dan Kebijakan Pertanian: Bogor.

Kavie. 2009. Pengertian Pendidikan, (Internet)

design.indonesianforum.net.htm).

Martini, T., Setyono, B., Sudarmaji. 2011. "Dampak Erupsi Gunung Merapi Terhadap Usahatani Bunga Krisan". Balai Pengkajian Teknologi Pertanian:Yogyakarta.
Nawawi, Hadar. 2004. Metode Penelitian Bidang Sosial. Yogyakarta: Gadjah Mada University Press.

Rovicky. 2010. Gunung Sinabung Bangun Setelah Tidur 400 tahun. (Internet). (http://rovicky.wordpress.com, diakses tanggal 22 Agustus 2011 pukul 14:30 WIB).

Silalahi, Ulber. 2009. Metode Penelitian Sosial.Bandung : PT Refika Aditama 